\title{
Medical faculties' view about the importance of educational roles
}

This article was published in the following Dove Press journal:

Advances in Medical Education and Practice

\author{
Samaneh Abolbashari ${ }^{1,2}$ \\ Hossein Karimi Moonaghi ${ }^{3,4}$ \\ Mojtaba Mousavi Bazzaz \\ 'Department of Medical Education, \\ Medical Faculty, Mashhad University \\ of Medical Sciences, Mashhad, Iran; \\ ${ }^{2}$ Students Research Committee, \\ Mashhad University of Medical \\ Sciences, Mashhad, Iran; ${ }^{3}$ Evidence - \\ Based Caring Research Center, \\ Department of Medical Surgical \\ Nursing, School of Nursing and \\ Midwifery, ${ }^{4}$ Department of Medical \\ Education, School of Medicine, \\ Mashhad University of Medical \\ Sciences, Mashhad, Iran; ${ }^{5}$ Department \\ of Community Medicine, Medical \\ Faculty, Mashhad University of Medical \\ Sciences, Mashhad, Iran
}

Correspondence: Mojtaba Mousavi Bazzaz

Department of Community Medicine, Medical Faculty, Mashhad University of Medical Sciences, Mashhad, Iran

Tel +985138002407

Email mousavim@mums.ac.ir
Background: Changes in medical education have drawn attention to student-based learning. It is necessary that teachers' educational roles be redefined to conform to these changes. While numerous educational activities are listed for medical teachers, it seems that they involve themselves in only some of these roles. We conducted this study to assess the importance of different educational roles in the view of medical faculties.

Methods: A questionnaire that consisted of a total of 12 roles classified into six categories including information provider, role model, facilitator, examiner, planner, and resource developer was prepared. Faculty members were asked to score the importance of each role using a 1-10 scale. Results: Participants assigned the highest score to "on-the-job role model" (9.47) and the lowest score to "curriculum planner" (8.31) from their own point of view. They also assigned the highest score to "planning or participating in student exams" (8.10) and the lowest score to "learning facilitator" (6.51) from the perspective of the importance of roles in their school's programs.

Conclusion: Faculty members are generally familiar with different educational roles but they need to be informed about some of the roles which have gained lower scores in this study.

Keywords: medical education, faculty member, teacher role

\section{Introduction}

Medical education has changed dramatically in the past two decades, and attention has been drawn to integrated teaching, problem-based learning, and new methods of assessment. There is also an emphasis on student-based learning. ${ }^{1}$ These changes ultimately lead to new demands, and propel responsibilities of faculty members to new levels of complexity and diversity. ${ }^{2}$ As one of the important elements of teaching and learning is different roles of teachers, ${ }^{3}$ it is necessary that teachers' roles be redefined to conform with these changes. It is also important to ensure medical teachers that in the shift from "teacher-based" to "student-based" learning, their roles are only "changed" and are certainly not devaluated.

Experts believe that a teacher in medical education needs to perform numerous educational activities. ${ }^{4}$ Lecturing in the classroom, role modeling, mentoring, and assessment and curriculum planning are among the various educational roles enumerated for medical teachers. However, it seems that faculty members - especially clinicians - involve themselves in only some of these roles and omit others, either because of lack of time or being unfamiliar with different roles. The reason might be that some faculty members have had no formal preparation for teaching. ${ }^{5}$ 
Harden and Crosby have listed 12 roles for teachers in medicine, classified in six categories. ${ }^{1}$ They have discussed the relative importance of each role and have noted that a teacher might have expertise in some roles and not the others. They have also suggested that a questionnaire could be prepared to obtain faculty members' view about their current roles and preferred roles so that teaching roles could be allocated properly within an institution. To our knowledge, no study has performed such a survey yet. We conducted this study to assess the importance of different educational roles in the view of faculty members of Mashhad University of Medical Sciences.

In Mashhad University of Medical Sciences, a reform in medical education was launched in 2012 by order of the Ministry of Health and Medical Education. The purpose of the reform is generally longitudinal and vertical integration of courses. Universities are also recommended to take into account "student-based learning" and "problem-based learning" when reforming the curricula. On the other hand, various workshops are held for faculty members for more adjustment with the mentioned changes. We, therefore, suppose that faculty members who take part in this study will not be unfamiliar with any of the educational roles they are asked to score.

\section{Methods}

This cross-sectional descriptive and analytical study was accomplished in Mashhad University of Medical Sciences, Iran, during February to June 2017.

To obtain a complete list of educational roles in the field of medical education, we searched the databases of MEDLINE, Scopus, and ScienceDirect with the keywords medical education, faculty member, and teacher role. Search results showed that a variety of roles are defined for medical teachers. We only selected the studies that contained roles relevant to education. The most complete list of faculty educational roles was presented by Professor Harden. ${ }^{1}$ A questionnaire was designed based on that article and was used as the data collection tool to assess the faculty members' idea about the importance of each educational role. The validity of the questionnaire was confirmed after 10 specialists in medical education reviewed and verified it. Also, the reliability of the questionnaire was confirmed after 15 faculty members were asked to complete it (Cronbach's $\alpha=0.76$ ).

The sample size was calculated to be 100 people. The number of faculty members assigned from each of the five schools to take part in the study was relevant to the ratio of faculty members of that school to the total number of faculty members in the university. Inclusion criteria consisted of all faculty members of Mashhad University of Medical Sciences who have been working in the university for at least 3 years and who were interested in taking part in the study. Participants were selected randomly from a list in which a code was specified to each faculty member. If a selected faculty member denied participating in the study, the next member on the list was selected. Written informed consent was obtained from all participants.

The questionnaire consisted of a total of 12 roles classified in six categories. The six categories were information provider, role model, facilitator, examiner, planner, and resource developer. Faculty members were asked to score the importance of each role using a 1-10 scale. They were asked to score the roles first from their own point of view and then the importance of them in the programs of the school they worked in. A sample of the questionnaire is shown in Figure 1.

After the completion of questionnaires, data were entered in and analyzed using SPSS 18.

The study was approved by the Medical Ethics Committee of Mashhad University of Medical Sciences with the code IR.MUMS.fm.REC.1395.146.

\begin{tabular}{|l|l|l|}
\hline \multicolumn{3}{|l|}{$\begin{array}{l}\text { Dear faculty member, Please score the importance of each } \\
\text { educational role listed below using a 1-10 scale. }\end{array}$} \\
\hline Educational role & $\begin{array}{l}\text { Importance } \\
\text { from your } \\
\text { point of view }\end{array}$ & $\begin{array}{l}\text { Importance in } \\
\text { your school's } \\
\text { programs }\end{array}$ \\
\hline Information provider & & \\
\hline 1. Lecturer in classroom & & \\
\hline 2. Teacher in clinical setting & & \\
\hline Role model & & \\
\hline $\begin{array}{l}\text { 3. On-the-job role model } \\
\text { (e.g., in clinics and ward } \\
\text { rounds) }\end{array}$ & & \\
\hline $\begin{array}{l}\text { 4. Role model in teaching } \\
\text { setting }\end{array}$ & & \\
\hline Facilitator & & \\
\hline 5. Mentor or tutor & & \\
\hline 6. Learning facilitator & & \\
\hline Examiner & & \\
\hline $\begin{array}{l}\text { 7. Planning or participating } \\
\text { in student exams }\end{array}$ & & \\
\hline 8. Curriculum evaluator & & \\
\hline Planner & & \\
\hline 9. Curriculum planner & & \\
\hline 10. Course organizer & & \\
\hline Resource developer & & \\
\hline 11. Production of study guide & & \\
\hline $\begin{array}{l}\text { 12. Production of learning } \\
\text { resources (multimedia, } \\
\text { book, and so on) }\end{array}$ & & \\
\hline
\end{tabular}

Figure I Sample of the questionnaire used to assess the importance of educational roles 


\section{Results}

One hundred faculty members from five schools participated in the study. Men and women faculty members comprised $62 \%$ and $38 \%$, respectively. Eight participants were faculties of nursery and obstetric school, 66 of medical school, seven of para medicine school, five of pharmacy school, and 14 of Dentistry School of Mashhad University of Medical Sciences. Lecturers, assistant professors, associate professors, and full professors comprised five, 45, 32, and 17 members, respectively. Faculty members had between 1 and 32 years of work experience with an average of $11.48 \pm 8.86$ years.

The average of the scores given to each role is shown in Table 1.

Faculty members assigned the highest score to "on-thejob role model" (9.47) and the lowest score to "curriculum planner" (8.31) from their own point of view. They also assigned the highest score to "planning or participating in student exams" (8.10) and the lowest score to "learning facilitator" (6.51) from the perspective of the importance of roles in their school's programs.

The average of scores given to each column was compared to each other. There was a weak correlation between the importance of roles in university programs and the importance of roles in faculties' point of view investigated by Pearson product-moment correlation $(r=0.265, p=0.008)$.

Also, the average of the scores assigned to each role and their relation to the sex, position, school, and years of working experience of faculty members are shown in Table 2. As shown in the table, there is no statistically significant difference between scores according to the mentioned variable.

Table I Average of the scores assigned to each role

\begin{tabular}{lll}
\hline Educational role & $\begin{array}{l}\text { Importance } \\
\text { from } \\
\text { faculties' } \\
\text { point of view }\end{array}$ & $\begin{array}{l}\text { Importance } \\
\text { in the faculty } \\
\text { members' school } \\
\text { programs }\end{array}$ \\
\hline Lecturer in classroom & 8.32 & 7.85 \\
Teacher in clinical setting & 9.34 & 7.75 \\
On-the-job role model & 9.47 & 7.64 \\
Role model in teaching setting & 9.36 & 7.69 \\
Mentor or tutor & 8.62 & 6.76 \\
Learning facilitator & 8.44 & 6.51 \\
Planning or participating in & 8.67 & 8.10 \\
student exams & & \\
Curriculum evaluator & 8.43 & 7.42 \\
Curriculum planner & 8.31 & 7.12 \\
Course organizer & 8.53 & 7.46 \\
Production of study guide & 8.43 & 6.61 \\
Production of learning resources & 8.35 & 6.57 \\
Average & 8.69 & 7.29 \\
\hline
\end{tabular}

Only two exceptions are seen: women faculty members have assigned a higher score to "role model" than men ( $p=0.025)$, and lecturers scored the role "examiner" higher than faculty members with higher university positions ( $p=0.037)$.

\section{Discussion}

In the current study, 12 educational roles for faculty members who work in the field of medicine were categorized into six groups, and the importance of the roles was assessed from the faculties' point of view.

There was an overall concordance between the views of faculty members of the five schools that we studied. This means that the university's educational programming has had a similar impact on all faculty members in different schools.

In general, faculty members scored the importance of all educational roles higher in their own point of view than in their schools' programs. There was only $7 \%$ correlation between the two sets of scores. This means that they believe that the school they work in does not evaluate these roles as much as they themselves do. The discordancy could be attributed to the university policies that consider research outputs more important than educational activities. ${ }^{6}$ It can be concluded that although Mashhad University of Medical Sciences has the tendency to change the curricula from teacherbased to student-based and keeps encouraging faculties to adapt themselves to the changes, because research activities and research products have stronger impact in making decisions about a faculty member's promotion or tenure, faculty members have assigned lower scores to each role in their school's programs.

The results relevant to each role will be discussed separately:

\section{Information provider}

This role was questioned by two aspects: lecturer in the classroom and teacher in clinical setting. Although faculty members have given a relevantly high score (8.32) to lecturing in classrooms, the score given to teaching in clinical settings is much higher (9.34).

This finding is relevant to what Harden and Crosby have discussed. They believe that although there has been a general call for a reduction in the number of lectures scheduled in the curriculum in the past decade, the complete exclusion of it is not wise. They have also noted that the clinical setting is a powerful context for transmitting the information directly relevant to the practice of medicine. ${ }^{1}$ We showed that faculty members of Mashhad University believe that lecturing in 
Table 2 Average of the scores assigned to each role in accordance with the sex, position, school, and years of working experience of faculty members

\begin{tabular}{|c|c|c|c|c|c|}
\hline \multirow[t]{3}{*}{ Role } & \multirow{3}{*}{$\begin{array}{l}\text { Statistical } \\
\text { test }\end{array}$} & \multicolumn{4}{|l|}{ Variable } \\
\hline & & Sex & Position & School & Years of working \\
\hline & & Student's t-test & ANOVA & ANOVA & ANOVA \\
\hline Information & Average & Men: 8.8I & Lecturer: 8.58 & Nursery: 8.12 & I-6 years: 8.53 \\
\hline \multirow[t]{5}{*}{ provider } & & Women: 8.8I & Assistant professor: 8.65 & Medical: 8.70 & $7-12$ years: 9.24 \\
\hline & & & Associate professor: 8.79 & Para medicine: 9 & Over 13 years: 8.83 \\
\hline & & & Full professor: 9.32 & Pharmacy: 9.30 & \\
\hline & & & & Dentistry: 9.42 & \\
\hline & $P$-value & 0.9996 & 0.310 & 0.136 & 0.090 \\
\hline \multirow[t]{6}{*}{ Role model } & Average & Men: 9 & Lecturer: 9.25 & Nursery: 9.43 & I-6 years: 9.39 \\
\hline & & Women: 9.59 & Assistant professor: 9.58 & Medical: 9.33 & $7-12$ years: 9.20 \\
\hline & & & Associate professor: 8.79 & Para medicine: $8.7 \mathrm{I}$ & Over 13 years: 9.07 \\
\hline & & & Full professor: 9.17 & Pharmacy: 8.60 & \\
\hline & & & & Dentistry: 9.21 & \\
\hline & $P$-value & 0.025 & 0.093 & 0.505 & 0.527 \\
\hline \multirow[t]{6}{*}{ Facilitator } & Average & Men: 8.49 & Lecturer: 8.66 & Nursery: 8.62 & I-6 years: 8.48 \\
\hline & & Women: 8.62 & Assistant professor: 8.50 & Medical: 8.54 & $7-12$ years: 8.28 \\
\hline & & & Associate professor: 8.34 & Para medicine: 7.78 & Over 13 years: 8.80 \\
\hline & & & Full professor: 8.97 & Pharmacy: 9.30 & \\
\hline & & & & Dentistry: 8.57 & \\
\hline & $P$-value & 0.627 & 0.430 & 0.377 & 0.288 \\
\hline \multirow[t]{6}{*}{ Examiner } & Average & Men: 8.47 & Lecturer: 9.16 & Nursery: 9.18 & I-6 years: 8.13 \\
\hline & & Women: 8.67 & Assistant professor: 8.06 & Medical: 8.57 & $7-12$ years: 8.40 \\
\hline & & & Associate professor: 8.90 & Para medicine: 7.87 & Over 13 years: 8.69 \\
\hline & & & Full professor: 8.97 & Pharmacy: 9.30 & \\
\hline & & & & Dentistry: 8.21 & \\
\hline & $P$-value & 0.508 & 0.037 & 0.295 & 0.081 \\
\hline \multirow[t]{6}{*}{ Planner } & Average & Men: 8.56 & Lecturer: 8.58 & Nursery: 8.31 & I-6 years: 8.13 \\
\hline & & Women: 8.16 & Assistant professor: 8.15 & Medical: 8.37 & $7-12$ years: 8.40 \\
\hline & & & Associate professor: 8.5। & Para medicine: 8.07 & Over 13 years: 8.79 \\
\hline & & & Full professor: 8.87 & Pharmacy: 7.87 & \\
\hline & & & & Dentistry: 9 & \\
\hline & $P$-value & 0.200 & 0.390 & 0.552 & 0.170 \\
\hline Resource & Average & Men: 8.47 & Lecturer: 8.75 & Nursery: 8.56 & I-6 years: 8.22 \\
\hline \multirow[t]{5}{*}{ developer } & & Women: 5.25 & Assistant professor: 8.32 & Medical: 8.37 & $7-12$ years: 8.22 \\
\hline & & & Associate professor: 8.14 & Para medicine: 7.78 & Over 13 years: 8.75 \\
\hline & & & Full professor: 8.39 & Pharmacy: 8.62 & \\
\hline & & & & Dentistry: 8.57 & \\
\hline & $P$-value & 0.452 & 0.235 & 0.783 & 0.217 \\
\hline
\end{tabular}

Abbreviation: ANOVA, analysis of variance.

the classroom is important; yet, clinical teaching has a more important role.

Yeh and Cahill have discussed that most clinician educators have a high degree of career satisfaction, which may be due to teaching's intrinsic rewards. ${ }^{?}$

\section{Role model}

Role modeling is accepted as a powerful means of transmitting values, attitudes, and patterns of thoughts and behavior to students. ${ }^{1}$ It is also an effective strategy for the development of medical professionalism. ${ }^{8}$

"On the job role model" and "role model in teaching class" were two extents of role modeling, which we asked faculty members to score. The average score for "on the job role model" was 9.47, which was the highest score in all roles. This shows the importance of role modeling from faculty perspective; they are aware of the influence it can have on the students' future carrier choices. A review study showed that physicians often state that faculty role models are influential in specialty choices, although a single faculty-student interaction is not proven to be important. ${ }^{9}$

In our study, women faculty members assigned a higher score to "role modeling" than men.

This difference could be attributed to "gender role expectations", which is discussed in some studies. In a study meant to analyze the experience of women faculty members 
in medicine, some stated that they were overloaded with having to guide students, particularly those with problems..$^{10}$ On the other hand, this difference could be attributed to the fact that women faculty members are more concerned about the impact their behavior might have on students' attitudes and behaviors.

\section{Facilitator}

Facilitation of learning and mentoring/tutoring were two roles in this group. Faculty assigned a mean score of 8.53 to these roles. The lower score dedicated in comparison to role modeling could be either because of lack of time or the imprecise definition of mentoring in faculties' minds. Although an "advisor professor" is assigned for each student in most Iranian medical schools, a study showed that $90 \%$ of students and faculties believe that the current system of student advisement is not efficient. The reason stated in the study was that students did not know how and when to get help from their advisors. ${ }^{11}$ Therefore, it is necessary that both faculty and students be taught about the true definition and methods of mentoring. On the other hand, "learning facilitator" is an important role in "problem-based learning". ${ }^{1}$ Faculty might not have assigned a very high score to this role because they have not yet involved themselves in this method of teaching.

\section{Examiner}

Assessment is becoming more and more important because society is increasingly demanding accountability from its doctors. ${ }^{12}$ Assessment is a distinct area of activity for medical teachers. The increasing number of assessment instruments makes it necessary for universities to include among their staff those who have a specialty in assessment. ${ }^{1}$ In our study, faculty assigned the highest score to "planning or participating in student exam" in their school's programs. This shows that they believe that assessment is either the most important responsibility the university wants them to undertake or the role that their school wants them to dedicate their most time for. Either one proven to be true rises the need for training programs to increase faculties' knowledge about the new methods of assessment. "Curriculum evaluation" is also an important responsibility of faculties to monitor the effectiveness of teaching. Faculty was aware of its importance, as they assigned a similar score to this role as for "planning or participating in student exam".

Also, lecturers assigned a higher score to the role "examiner" than faculty members with higher university positions ( $p=0.037$ ). This might be because lecturers are less involved in research activities and possess more time to allocate to the evaluation of students.

\section{Planner}

"Curriculum planner" and "course organizer" were two roles in this theme. The relatively low score given to these roles indicates that faculty is unaware of the great impact these activities have on learning. On the other hand, lack of time might be the reason. In a study in Iran, only $50 \%$ of faculty members of a medical university had prepared written lesson plans for the courses they taught. ${ }^{13}$ In another study, faculty stated that their high workload, low impetus, and not having enough knowledge about writing a lesson plan are among the reasons that prevent them from writing them. ${ }^{14}$

\section{Resource developer}

A fundamental part of student-based learning is the availability of resource material. ${ }^{1}$ On the other hand, study guides that could be used for both undergraduate and postgraduate education could compensate the limited time for face-toface contact with students and teachers, which is necessary for learning. In this study, "production of study guides" and "resources" has gained relatively low scores, which reflect the fact that faculty members are unaware of their importance and schools have not involved faculties in their preparation. These roles had gained low scores in Harden and Crosby's study too. ${ }^{1}$ It seems necessary to highlight the important role of study guides in education, both for students and teachers.

Overall, faculty members believe that clinical teaching and role modeling are more important than other roles, while their school programs indicate participation in student exams and classroom lectures. The discordance between what faculty thinks is important and what they express about their school programs brings up the fact that probably programs need to be revised and faculty duties are reconsidered.

A general problem in medical education reported by many educators around the world is that training that concentrates on acquiring knowledge and skills may not necessarily result in a competent practitioner. ${ }^{15}$ Therefore, medical educators need to focus on methods of teaching, which result in higher competency.

Another problem especially in academic hospitals is that the burden of needing proficiency but the lack of opportunities to learn necessary skills falls more heavily on junior faculty members. ${ }^{16}$ Hence, if universities are seeking better medial education, it is necessary to provide junior faculty the learning opportunities they require. As many opportunities are provided to improve teaching skills, the next generation 
of faculty should be encouraged and supported to avail themselves of these opportunities for continued growth and development. ${ }^{17}$

\section{Conclusion}

In general, faculty members have a good view about the different educational roles, but they need to be acknowledged about some roles that have gained lower scores in this study. It is the responsibility of universities to hold relevant workshops for this mean and to encourage teachers to involve themselves in the roles that are less considered. Universities would, therefore, benefit from using a method of evaluating and equating faculty efforts in both educational and clinical areas. It will also be beneficial if rewards and penalties for the quality of faculty efforts in education are factored into the calculations that lead to their promotions.

Further research to evaluate the effect of changes in curricula on what faculty members think about their different roles is recommended.

\section{Disclosure}

The authors report no conflicts of interest in this work.

\section{References}

1. Crosby J, Harden R. AMEE Guide No 20: the good teacher is more than a lecturer - the twelve roles of the teacher. Med Teach. 2000;22(4):334-347.

2. Scheid DC, Hamm RM, Crawford SA. Measuring academic production. Fam Med. 2002;34(1):34-44.

3. Bigdeli S, Boushehri E, Biabangardy Z. Global medical teacher. Procedia Soc Behav Sci. 2012;47:1981-1984.

4. Hesketh EA, Bagnall G, Buckley EG, et al. A framework for developing excellence as a clinical educator. Med Educ. 2001;35(6):555-564.
5. Johnson-Farmer B, Frenn M. Teaching excellence: what great teachers teach us. J Prof Nurs. 2009;25(5):267-272.

6. Dadman M, yamani N, changiz T, Mosavi A. The performance of faculty members about scholarship of teaching inIsfahan university of medical sciences during 2009-2012. IJME. 2014;14(6):527-538.

7. Yeh MM, Cahill DF. Quantifying physician teaching productivity using clinical relative value units. J Gen Intern Med. 1999;14(10): 617-621.

8. Passi V, Johnson S, Peile E, Wright S, Hafferty F, Johnson N. Doctor role modelling in medical education: BEME Guide No. 27. Med Teach. 2013;35(9):e1422-e1436.

9. Campos-Outcalt D, Senf J, Watkins AJ, Bastacky S. The effects of medical school curricula, faculty role models, and biomedical research support on choice of generalist physician careers: a review and quality assessment of the literature. Acad Med. 1995;70(7):611-619.

10. Pololi LH, Jones SJ. Women faculty: an analysis of their experiences in academic medicine and their coping strategies. Gend Med. 2010;7(5):438-450.

11. Seyedmajidi M, Jahanian I, Moradi N, Bijani A. Survey of Babol medical students' view about faculty members' consultation and guidance activity. J Med Educ Dev. 2013;8(2):1-14.

12. Fluit CR, Bolhuis S, Grol R, Laan R, Wensing M. Assessing the quality of clinical teachers: a systematic review of content and quality of questionnaires for assessing clinical teachers. J Gen Intern Med. 2010;25(12):1337-1445.

13. Nikbakhsh, N, Amri, P, Mohammadi Kenari H, Razzaghi F. Evaluation of lesson plans of faculty members of medical and dental schools of Babol university of medical sciences. JBUMS. 2010;12(5):14-18.

14. Magidishad B, Asdi Louye A, Nemati MAJ. Assessment of Faculty members' viewpoint about writing and doing daily lesson plan in Guilan university of medical sciences. 4th Iranian Congress of Medical Education. 2000:120-126.

15. Dhaliwal U, Gupta P, Singh T. Entrustable professional activities: teaching and assessing clinical competence. Indian Pediatr. 2015;52(7):591-597.

16. Flanders SA, Centor B, Weber V, McGinn T, Desalvo K, Auerbach A. Challenges and opportunities in academic hospital medicine: report from the academic hospital medicine summit. J Gen Intern Med. 2009;24(5):636-641.

17. Sklar DP. Just because i am teaching doesn't mean they are learning: improving our teaching for a new generation of learners. Acad Med. 2017;92(8):1061-1063.
Advances in Medical Education and Practice

\section{Publish your work in this journal}

Advances in Medical Education and Practice is an international, peerreviewed, open access journal that aims to present and publish research on Medical Education covering medical, dental, nursing and allied health care professional education. The journal covers undergraduate education, postgraduate training and continuing medical education

\section{Dovepress}

including emerging trends and innovative models linking education, research, and health care services. The manuscript management system is completely online and includes a very quick and fair peer-review system. Visit http://www.dovepress.com/testimonials.php to read real quotes from published authors. 